\title{
FEATURE
}

\section{Cyberspace or Face-to-Face}

The Teachable Moment and Changing Reference Mediums

\section{Christina M. Desai and Stephanie J. Graves}

Christina M. Desai is Reference and Instruction Librarian, University of New Mexico, Albuquerque. Stephanie J. Graves is Humanities Reference Librarian, Southern Illinois University, Carbondale. Submitted for review September 14, 2006; accepted for publication November 30, 2006.

Reference \& User Services Quarterly, vol. 47, no. 3, pp. 242-254

(c) 2008 American Library Association. All rights reserved.

Permission granted to reproduce for nonprofit, educational use.
This article considers the teaching role of reference librarians by studying the teachable moment in reference transactions, and users' response to that instruction. An empirical study of instruction was conducted in both virtual and traditional reference milieus, examining the following three services: Instant messaging (IM), chat, and face-to-face reference. The authors used the same criteria in separate studies of all three services to determine if librarians provided analogous levels of instruction and what factors influenced the likelihood of instruction. Methodologies employed included transcript analysis, observation, and patron surveys. Findings indicated that patrons wanted instruction in their reference transactions, regardless of medium, and that librarians provided it. But instructional techniques used by librarians in virtual reference differ somewhat from those used at the reference desk. The authors conclude that reference transactions, in any medium, represent the patron's point-of-need, thereby presenting the ideal teachable moment. 
Do librarians at the reference desk provide more instruction than their virtual counterparts? Do they provide it more often? Are they taking advantage of potential teachable moments?

In today's ideal reference model, librarians show patrons how to find information rather than simply provide answers. RUSA's "Guidelines for Behavioral Performance of Reference and Information Service Providers" emphasizes the importance of instruction in all reference environments, including virtual reference. ${ }^{2}$ We might assume that it is simpler to provide instruction faceto-face and therefore more common at the reference desk, but is this true? The authors examined this question as it relates to IM and chat reference in two recent studies. "Chat" was defined as commercial software developed for libraries, and "IM" as free or home-grown messaging software without co-browse capability. The current study builds on the two previous studies by comparing IM and chat instruction to instruction at the traditional reference desk, using the same criteria.

The purpose of the first study, conducted in 2005, was to gauge the amount of instruction being offered through IM reference. ${ }^{3}$ Using transcript analysis and a user survey, the authors determined how often librarians provided instruction and under what conditions they were most likely to provide it. They also inquired about patrons' desire for and willingness to receive instruction as well as their perception of actual learning. The authors also developed a classification of teaching techniques employed by librarians and measured the frequency of their use.

The following summer the homegrown software for the service was replaced with commercial chat software with co-browsing capability. To test whether the co-browsing feature made a difference in the amount and type of instruction offered through chat, the authors conducted a second study, comparing the results using the new software to the original home-grown product. ${ }^{4}$ The same criteria and methodology were used to evaluate the likelihood and frequency of instruction, but this time the effect of co-browsing both on instruction and on patrons' perception of learning was also studied.

The purpose of the present study is twofold. First, it compares the frequency and types of instruction that occur during reference in two mediumstraditional (in person) and virtual (IM and chat) reference. Secondly, as with the previous studies, it also gauges whether users want or are willing to accept instruction and whether they feel they learned anything from the reference transaction. The current study of the physical reference desk follows as closely as possible the methodology used in the first two studies of the virtual reference milieu.

\section{LITERATURE REVIEW}

Studies assessing information literacy programs and traditional bibliographic instruction (BI) classes abound. But few studies have actually measured the instructional activity at the reference desk. Jacoby and O'Brien's study touches on instruction as one aspect of assessing reference service. It surveyed undergraduates and found that nearly 64 percent of participants "learned about new resources during the reference encounter" and many also acquired strategies for finding information. ${ }^{5} \mathrm{Ja}-$ coby and O'Brien's approach suggests that a change in reference philosophy has occurred. In the past, rather than being focused on effective instructional techniques, debate centered on whether librarians should be teaching at the reference desk at all.

Schiller provided one of the early arguments against instruction during reference work. In a 1965 article she argued that the primary job of librarians is to exercise professional skill by finding and providing information and by selecting new resources based on patron needs; according to this view, expecting patrons to spend their own time searching is a betrayal of professional responsibility. ${ }^{6}$ She pointed out that instructing patrons in self-service has sometimes been necessitated by a lack of resources for staffing, but also stems from a deeply rooted belief that librar- ies exist for patron self improvement; Schiller countered by saying that requiring patrons to submit to instruction (often cursory and dismissive) is a presumptuous imposition stemming from this moralistic attitude. As recently as 2001, Bill Katz, renowned guru of reference librarianship, agreed with Schiller's original position that "In the ideal situation, the reference librarian finds the answers for the user, rather than showing the user how to locate information," viewing this approach as the only way to avoid patron information overload and to achieve professional status for librarianship. ${ }^{7}$ Katz also asserted that at least 95 percent of library users do not want to find information for themselves and therefore should not be forced to learn. ${ }^{8}$ But, despite the eloquence of the above arguments, as early as 1982 Schiller had modified her thinking: "the growing complexity of libraries. new reference tools" and "heightened demands for information, have imposed new requirements for access, and bibliographic instruction has become one important mechanism for achieving them." Technological advances in the electronic organization of information have blurred the distinction between searching and finding. Electronic database searching is an iterative process of discovery. Skill is needed to exploit database features to their fullest, and to refine the search more precisely after viewing an overwhelming number of preliminary results. Such skills can be learned and may be necessary to combat information overload; therefore instruction is beneficial and becomes an integral part of reference service.

In a study of the impact of technology on instruction published in 1995 , Tenopir found that academic librarians were spending more time, not less, on instruction, particularly on one-on-one instruction, because of the new electronic formats. But one of Tenopir's survey respondents also felt librarians should have been spending more time teaching all along. She believed that recommending a particular index was not sufficient because the patron's search was still often unsuccessful. Tenopir stated that "These librarians feel tech- 


\section{FEATURE}

nology helped get them out of a bad habit of assuming everyone was getting satisfactory results once they had been directed to a resource or taught the rudiments of its use." 10

Those were the early days of adjusting to electronic sources. The proliferation of technology starting in the 1980s blurred the lines between providing traditional reference and providing technical assistance. Many had supposed that online information systems would obviate the need for traditional reference altogether. ${ }^{11}$ Yet newer interfaces designed for end users made instruction more crucial than ever because librarians found they could not expect patrons to find, navigate, and evaluate electronic systems without help. In a review article, Hope, Kajiwara, and Liu asserted that the advent of the Internet has expanded, not reduced, the librarian's instructional role. ${ }^{12}$ Tyckoson believes that "the complexity of the modern library requires us to continually re-instruct existing library users. New technologies, new services, and new sources are not self-evident, even to the most experienced users. . . Instruction is now more important and more central to the role of the library than it has been at any time in the past, and there is no reason to believe that this need will change in the future." 13

Today online sources have become so ubiquitous that most students have never used a print index. While it is true that electronic sources have become more user friendly, training and hands-on practice are as important as ever. An Elsevier study of user behavior found that "A higher level of search skills (and greater knowledge of literature) gained through experience and training enabled senior researchers to answer questions and locate key articles in an average of 5-10 minutes instead of the 30-60 required by graduate students." ${ }^{14}$ If graduate students in science and technology disciplines, presumably fairly computer literate and at least somewhat experienced with research, are performing inefficient and unsuccessful searches, it is likely that undergraduates are even more at a loss. It seems safe to conclude the need for instruction does not diminish with improvements in technology. Yet many students fail to realize they need help learning how to do research. In an article applying competency theory to the reference situation, Gross suggests that the least competent information seekers are also the least likely to recognize their need for guidance and instruction in their information search. ${ }^{15}$

Today most librarians, at least in academia, would agree that instruction is needed. Emphasis has therefore shifted in recent years to studying formal bibliographic instruction in the classroom setting. But some argue that point-ofneed assistance is more effective than formal classes. In a focus group study at Johns Hopkins, Massey-Burzio found that students were dissatisfied with reference when "Information Desk staff did not go to the computers with them to explain things." ${ }^{16}$ She argues that pointof-need assistance is more successful than classroom instruction. Saunders found that bibliographic instruction may make a more sophisticated, but not necessarily a more self-sufficient, searcher. He found that "the number of reference questions will increase by anywhere from two to seven questions for each person receiving bibliographic instruction." 17 These figures bear out Gross's prediction that those given some bibliographic instruction will recognize the need for more. McCutcheon and Lambert echo this connection, calling for more communication between classroom instructional librarians and reference librarians to increase learning opportunities at the reference desk. ${ }^{18}$

In a compelling article, applying constructivist learning theory to instruction at the reference desk, Elmborg argued that "the reference desk can be a powerful teaching station-more powerful, perhaps, than the classroom."19 He argued that providing answers outright defeats learning by leaving patrons continually dependent on librarians' help. He further maintains that to earn and maintain professional status in the academy, librarians must be seen first and foremost as educators, like other faculty, who impart rather than withhold their specialized knowledge and empower the learner to "construct" their own learning. ${ }^{20}$ It is therefore up to reference librarians to recognize the need for instruction and provide it.

Like studies of instruction at the reference desk, studies of instruction via chat reference are very few. This lack of research is surprising given that RUSA's "Guidelines for Behavioral Performance of Reference and Information Service Providers" stresses the importance of instruction in all reference situations, regardless of the medium..$^{21}$ Several articles on using chat for instruction do not relate to chat reference services but to such applications as holding online office hours for distance learners or for supplementing online tutorials. ${ }^{22}$ Articles cited in the authors' previous research by Beck and Turner, Green and Peach, Ellis, Ward, and Woodard remain the primary examples of studies of instructing via reference, either with techniques specific to chat or by applying techniques from the physical reference desk to the virtual desk. ${ }^{23} \mathrm{~A}$ special issue of The Reference Librarian devoted to digital reference makes few mentions of instruction aside from the article on communication strategies. ${ }^{24}$ One author even cautioned that librarians who are used to providing detailed instruction via e-mail reference will "not have that luxury in chat reference." 25 Articles reporting on chat reference user satisfaction almost never ask about learning. One exception is an article by Broughton noting that of the 209 responses, 136 reported instances of learning (such skills as keyword vs. subject searching, search strategy construction, correct citation style, etc.). ${ }^{26}$

Some articles on chat reference services make passing mention of best practices that relate to learning, such as the article by Ronan, Peakes, and Cornwell in which chat transcript analysis revealed several instances of page pushing without any explanation of how to get to the page. ${ }^{27} \mathrm{~A}$ more recent article by Zhou, Love, Norwood, and Massia measured staff performance against RUSA's "Guidelines"; using a strict definition of instruction, they found only about two thirds of their transcripts showed evidence of teaching. ${ }^{28}$ These 
authors looked for instruction only in the transcripts related to research questions (70 percent), assuming that other question types do not call for instruction. A recent assessment article by Paster et al. takes a similar approach, using patron surveys to measure learning as one indication of patron satisfaction. ${ }^{29}$ But most assessment articles do not mention instruction, including the article by Novotny, which reviews various best practice guidelines by which to assess virtual reference quality. ${ }^{30}$

The present study appears to be the first to compare instructional activity for both physical and virtual reference mediums by applying the same criteria. This and the authors' previous two studies use both transcripts and survey data to determine librarian instructional activity. All three studies also measure patrons' attitude toward instruction and their perception of learning.

\section{RESEARCH METHOD}

When considering research method, the authors had to decide between an obtrusive or unobtrusive protocol, and make sure that necessary safeguards were in effect. Earlier empirical studies of reference focused on the accuracy of the answers provided. ${ }^{31}$ Later studies countered with work on what determines "satisfaction" and "willingness to return." ${ }^{2} 2$ To ensure impartiality, these studies used an unobtrusive method, which involved hiring proxy patrons to ask a set of predetermined, usually factual questions at various reference desks. The procedure is considered unobtrusive because the librarians are not informed that they are being tested, and therefore it is assumed that they do not alter their normal response.

Alternately, obtrusive studies may suffer from a phenomenon known as the Hawthorne effect. As usually summarized, this effect is the presumption that behavior of experimental subjects will change if they know they are being observed. The notion is based on industrial experiments conducted in the 1930s by Roethlisberger and Dickson in which production levels increased with changes in experimental conditions, regardless of what the changes were. ${ }^{33}$ Later reviews of this research found many overlooked factors at work, such as changes in pay structure, access to production totals, peer pressure, peer support, and increased skill. ${ }^{34}$ Finally, it was not the case that production increased with every change in conditions. ${ }^{35}$ In the many subsequent empirical studies of the Hawthorne effect, only a few could replicate the effect or support its validity ${ }^{36} \mathrm{~A}$ more important variable may be the subjects' perception of the purpose of the research and attitude toward that purpose. ${ }^{37}$ Thus, while it makes intuitive sense to assume that workers who are watched will put their best foot forward, it has not been conclusively proven that this is the case.

It is a truism of reference practice that patrons' initial questions seldom express their real information needs, and few questions asked in an academic library are strictly factual. ${ }^{38}$ While in an unobtrusive study, librarians may not alter their behavior, the behavior of proxy patrons remains an issue. Because their information needs are real, actual patrons will elaborate if the librarian probes, and will likely participate in the information-seeking process more actively than proxies. Jensen objects to the unobtrusive proxy method in studies of chat reference both because it is an unfair imposition on the resources of the library and also because it could result in skewed research results because "The chat discourse of an information professional or trainee presenting a sham query is very likely to differ from that of a genuine questioner." ${ }^{39}$ To avoid this artificiality, the authors chose obtrusive direct observation of real reference transactions at the physical reference desk. Jo Bell Whitlatch, in a study of reference research methodologies, recommends the obtrusive approach with the caveat that "Safeguarding against observational bias also requires training observers thoroughly and may require using more than one observer." ${ }^{\prime 0}$ She also advises using more than one method for each study "because the strengths of one method often compensate for the weaknesses of another." ${ }^{\prime 1}$ The current study implemented these safeguards by using three trained observers and unobtrusive patron surveys to corroborate results.

The authors' previous studies of virtual reference could be considered unobtrusive. Certainly, no one was physically present in the virtual librarian's office during reference transactions. But transcript analysis was not strictly unobtrusive. Librarians knew that their transcripts were stored and that those transcripts would be used for training and research. Much like the reference desk where other librarians can overhear conversations, online reference librarians are aware that other librarians can view their chat transcripts at any time. Therefore there is little difference in the degree of obtrusiveness between the two virtual studies and the study of the reference desk (referred to in the present study as the "information desk"). In all three studies, human-subjects compliance required informed consent of the subjects, that is, the librarians. If the observations did affect behavior, then they would likely have affected both mediums equally. It should also be noted that the observers were peers, not in a position of authority over the observed librarians. Observed librarians were told only that this was a study of reference, not that the researchers were looking for instances of instruction; nor were the observations or patron surveys shared with librarians.

Both librarians and paraprofessionals were observed, since both groups provided a substantial amount of reference service. The paraprofessionals were all long-term employees with considerable experience and expertise in providing reference service. Many of them readily volunteered to staff the IM service when it began and continue to staff both online and physical reference along with librarians. Names of service providers were not recorded in the data collected. For the sake of simplicity, all staff members will be referred to as librarians unless otherwise noted.

The authors developed an observation matrix of instructional activities based on studies 1 and 2, and conducted a pilot test for one week. As in 


\section{FEATURE}

the studies of virtual reference, each transaction was evaluated for instructional activity and assigned to one of six categories:

C1. Patron asked for and received instruction.

C2. Patron asked for but was not given instruction.

C3. Patron did not ask for but was given instruction.

C4. Patron did not ask for, and the librarian did not give instruction.

C5. No instruction was possible, given the nature of the question, for example, library policy questions.

C6. Instruction was not asked for, and not given, but was offered by the librarian.

Category 5 questions were eliminated from analysis since they have no bearing on instruction.

Categories were assigned based on patrons' initial queries. Questions such as "How do I . ...," "Can you help me find ...," and "Can you show me how ..." were defined as requests for instruction. Initial queries such as "Where is

." (asking for physical location), "Do you have ...," and statements such as "My article won't print" were defined as not asking for instruction. Providing instruction was defined as showing the patron how to search by one or more of the following activities: suggesting appropriate resources, terms, limits, etc.; leading the patron step-by-step through the research process; providing minilessons on the meaning of library jargon or concepts; or modeling the information seeking process by describing the full sequence of steps. In addition, observers collected data on actions analogous to co-browsing in chat reference, such as turning the screen toward the patron to demonstrate the steps in the search process, pointing to portions of the screen, or encouraging the patron to use the mouse or type into the search boxes. After minor modifications based on the pilot test, observations were conducted during the hours when chat reference was also offered. These hours were chosen as the busiest times of the day for both physical and virtual reference.

Observation of the information desk and coding were done by the authors and a graduate assistant hired for the purpose. Data collection was to have covered a seven-week period, as in the earlier two studies. Observation began as scheduled during the spring semester of 2006 during the hours when the chat service was also offered, for a total of twenty-nine hours of observation per week. During this period, the library was undergoing extensive renovation and part of the building was closed. While the noise, physical appearance, and reduced space in the library meant that fewer patrons used the library building, the information desk continued to function as usual.

An unforeseen construction problem forced an end to data collection during the sixth week. To ensure the safety of staff and library users, the building was temporarily shut down. Though temporary satellite reference desks were quickly set up in other locations on campus, the study had to be suspended because these desks were staffed for limited hours and mostly by graduate assistants. While it would have been very interesting to observe how well reference and instruction were being offered under these trying conditions, it could not be attempted because the graduate assistants had not been cleared for study by the campus human subjects committee. Despite the construction, the amount of data collected during these five weeks far exceeded the amount collected during the seven weeks of the virtual reference studies. Students still use the traditional reference desk far more than any form of virtual reference service. Analysis of the high volume of data collected at the traditional desk showed that the instructional patterns were similar from week to week, so we may assume that the missed weeks' observations would not have significantly affected the results.

As in the studies of IM and chat reference, information desk patrons were asked to fill out a survey. The surveys were designed to gauge users' attitudes toward receiving instruction and their perception of learning from the refer- ence transaction. The surveys were voluntary and anonymous. Patrons could be faculty, staff, students, or community members. In both study 1 and the current study, the patrons' surveys and their corresponding reference transactions were matched using the initial query. Knowing what happened during the reference transaction helped explain survey responses. This linking was not possible in study 2 due to limitations of the chat software. Results from the information desk and corresponding patron surveys were compared with results from studies 1 and 2 .

Data analysis was performed using Excel spreadsheet software. A chi-square analysis was used to determine statistical significance of comparable transcript data across the three studies. A $p$ value of $<.05$ was considered statistically significant. Chi-square analysis could not be done on individual categories Cl-C6 given low expected values $(<5)$ for some categories. Therefore, chi-square analysis was performed by grouping categories on the basis of instruction given versus not given. Similarly, chi-square analysis could not be done on the survey data given low expected values $(<5)$ for some categories.

\section{FINDINGS}

\section{Observation Matrix and Transcript Analysis}

The number of transactions at the reference desk far exceeded those in virtual reference. In study 1 , the study of IM service, 169 transcripts were reviewed. In study 2, the study of chat service with co-browse capability, 136 transcripts were reviewed. Study 3, the study of the information desk, recorded the most transactions with a total of 567 observations. Each transaction was coded for one of the six instructional categories.

In each case, reference transactions coded as C5 were removed from the total. C5 instances were those where instruction was not possible given the nature of the question or situation. An example would be asking for assistance in clearing a paper jam. Including C5 
would have skewed the results, since librarians cannot be held responsible for providing instruction in instances where it is not possible or appropriate. Eliminating C5 transcripts reduced the number of transactions in each study as follows:

1. study $1-146$ transcripts;

2. study $2-118$ transcripts; and

3. study 3-273 observations.

The information desk had a much greater percentage of $\mathrm{C} 5$ occurrences. In study 1, C5 questions accounted for 12 percent and in study 2, 13 percent of the questions. But in study 3, C5 transactions accounted for 52 percent of all recorded transactions. This corroborates anecdotal evidence from staff who often complain about spending time fixing printer problems and pointing out the location of the stapler. All subsequent statistics are based on total transactions minus $\mathrm{C} 5$.

Figure 1 depicts the percentage of each category in study 3 , the study of the information desk.

Of the 273 transactions, 46 percent were identified as $\mathrm{Cl}$ (patron asked for and received instruction). C3 (patron did not ask for but was given instruction) followed with 43 percent. Combining these two categories reveals that patrons received instruction 89 percent of the time. C4 accounted for only 6 percent, and $\mathrm{C} 2$ only 5 percent. As C2 and C4 represented a failure by the librarian to provide instruction, it is reassuring that, combined, they totaled a small fraction of the reference transactions (11 percent). There were no instances of C6 (instruction was not asked for, and not given, but was offered by the librarian).

Figure 2 compares studies 1, 2, and 3 by percentage of each category to gauge differences across the three reference mediums.

\section{C1: Patron Asked For and Received Instruction}

These transactions formed the largest group in all three studies, showing that patrons were asking for instruction, regardless of reference medium. Study 2 figures for $\mathrm{Cl}$ were 9 percent higher than in study 1. $\mathrm{Cl}$ transactions in study 3 were much closer to study l's figures. This discrepancy may be explained by the entry screen for chat reference in study 2. Transcript analysis revealed many patrons misinterpreted the entry screen in study 1 and used it as a site search or search engine, often entering a single keyword or phrase rather than a complete sentence or question. ${ }^{42} \mathrm{~A}$ query consisting of a single word could not be interpreted as a request for instruction. In study 2, patrons had to click on several icons and then fill out a form to enter chat reference. Conse- quently, patrons seemed to understand that they were asking a question of a librarian and phrased their queries accordingly. Problem statements, such as "My article won't print," were not coded as requests for instruction, and these occurred more often at the information desk. These two factors may account for the lower number of $\mathrm{Cl}$ transactions in studies 1 and 3 .

\section{C2: Patron Asked For But Was Not Given Instruction}

Transactions coded as C2 were lowest in study 1 at 2 percent and highest in study 3 at 5 percent. While the

Figure 1. Study 3

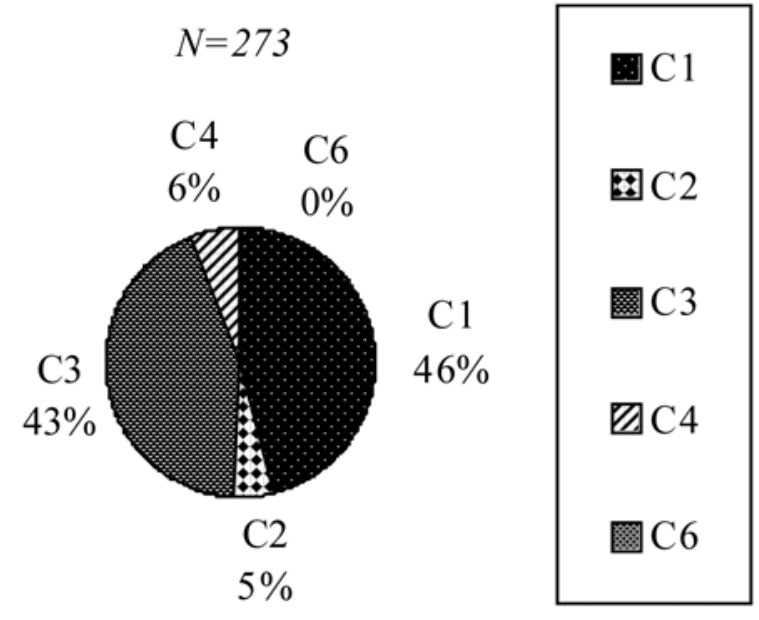

Figure 2. Instruction Categories by Study

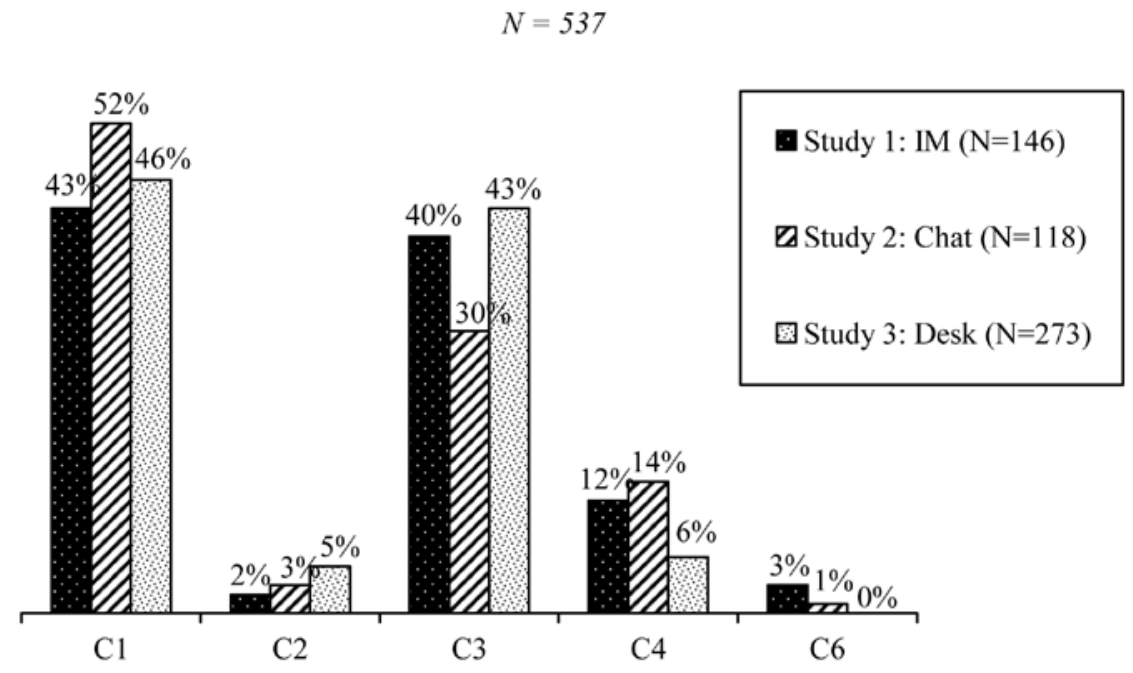

volume 47 , issue $3 \quad \mid \underline{247}$ 


\section{FEATURE}

numbers were remarkably low, this category does represent a failure of the librarian to provide instruction, even when asked to do so by the patron. The higher number of $\mathrm{C} 2$ transactions at the information desk is disturbing. Perhaps the heavy volume of questions at the desk reduced the time available for instruction. However, this is supposition only.

\section{C3: Patron Did Not Ask For But Was Given Instruction}

The largest discrepancy in any of the categories appeared in C3. C3 transactions dropped 10 percent from study 1 to study 2 (from 40 percent to 30 percent) then rose 13 percent in study 3 to 43 percent. Why the dip in study 2? As with the discrepancy in $\mathrm{Cl}$, the authors speculate that the difference was because of the more formalized chat entry screen in study 2 . There were no single-word or phrase queries in study 2. Single-word or phrase queries would have been coded as the patron not asking for instruction; these were prevalent in study 1 . The authors also speculate that the rise in study 3 may have to do with the social nature of the information desk. Patrons would not approach the librarian at the desk with a single word or phrase, as in study 1. But they were more apt to approach the librarian with a problem statement, which was coded as the patron not asking for instruction. Common examples were students who approached the information desk with the statement, "My account has been disabled." While these patrons clearly did not ask for instruction, librarians often conducted a detailed instructional session with these patrons to show them how to unlock and manage their network accounts.

\section{C4: Patron Did Not Ask For and the Librarian Did Not Give Instruction}

C4 transactions were relatively even in studies 1 and 2 (12 percent and 14 percent respectively). In study 3 , this particular category totaled 6 percent. This decrease is logical; since patrons at the information desk get instruction more often, the results in this category were lower, as expected.

\section{C6: Instruction Was Not Asked For, and Not Given, But Was Offered By the Librarian}

C6 dropped from 3 percent in study 1 to 1 percent in study 2 , and finally to 0 percent in study 3 . Transcript analysis of studies 1 and 2 showed that this category was assigned to transactions in which the online librarians first gave an answer, then offered instruction, but patrons logged off before the librarian could proceed. Similar behavior is unlikely to occur at the reference desk, where body language cues would alert librarians to patrons' openness to instruction, and social convention would prevent patrons from walking away without answering.

Did reference medium influence the likelihood of instruction? Combining specific categories helped answer this question. $\mathrm{Cl}$ and $\mathrm{C} 3$ represented transactions in which patrons received instruction. In study 1 , combining these two categories showed that patrons received instruction 83 percent of the time. Study 2 had an 82 percent rate of instruction. Study 3 ranked highest with 89 percent. While the rate of instruction remained remarkably similar across all three studies, instruction was slightly more likely at the physical information desk. A chi-square analysis performed on $\mathrm{Cl}$ plus $\mathrm{C} 3$ (instruction provided) against $\mathrm{C} 2$ plus $\mathrm{C} 4$ plus $\mathrm{C} 6$ (instruction not provided) showed that the differences were not statistically significant $(p>.05)$; that is, provision of instruction did not vary significantly by medium.

The results of studies 1 and 2 showed that patron-question format affected the likelihood of instruction. ${ }^{43}$ In both studies of virtual reference, patrons who asked for instruction $(\mathrm{Cl}$ and C2) received it 95 percent of the time. In study 3, patrons who asked for instruction in face-to-face reference received it 94 percent of the time. These consistent results show that the reference medium, be it virtual or physical, did not have an impact on the likelihood of instruction if the patron requested it.

Conversely, results showed that the reference medium did affect the likelihood of instruction for those patrons who did not ask for instruction, represented by C3, C4, and C6. C3 represented those who received instruction without asking for it. Therefore dividing $\mathrm{C} 3$ by the total for all three categories gives the rate of instruction when not requested. In a comparative analysis of study 1 and study 2 , the rates were 73 percent and 66 percent respectively. ${ }^{44}$ The authors hypothesize that the decrease was due to staff discomfort with the commercial chat product introduced shortly before study 2 began. The same hypothesis may explain the higher rate of instruction for those who did not ask for it (79 percent) in study 3. Librarians at the information desk have years of experience and are experts at that particular reference medium. They apparently feel comfortable asserting themselves and acting as instructors, even when not directly prompted by the patrons' queries. A chi-square analysis indicates a statistically significant difference in the rate of instruction when not requested across the IM, chat, and face-to-face mediums, $X^{2}(2, N=268)=12.67, p=.002$.

While the analysis above emphasizes the differences between virtual and physical reference mediums, it is worth noting that the percentages remain strikingly similar across all three studies. The authors feel confident that librarians at this library are providing instruction most of the time regardless of medium. If the goal is to provide consistent service, this data shows that librarians are on the right track. The reference medium did not significantly alter librarians' willingness or ability to provide instruction.

Does the likelihood of instruction differ, however, if the patron is served by a librarian as opposed to a paraprofessional? Librarians and paraprofessionals both staff in-person reference and virtual reference, and any inconsistency in service should be noted. The rate of instruction was determined by totaling $\mathrm{Cl}$ and $\mathrm{C} 3$ for librarians 
and for paraprofessionals, then dividing by the total number of transactions for that group. Information from study 2 showed that paraprofessionals provided instruction 74 percent of the time while librarians did so 87 percent of the time..$^{45}$ Study 3 mirrors these findings: paraprofessionals provided instruction 81 percent of the time and librarians 90 percent. The difference is understandable given that librarians are trained and dedicated to information literacy skills. Yet, however small, the difference indicates that more training is necessary for paraprofessionals if consistency of service is to be maintained.

Face-to-face reference has a component less readily available in virtual reference-the ability to confer with colleagues. Chat products often include the ability to hold private conversations with another librarian while helping a patron. Some chat platforms enable transferring patrons between online librarians. But both features require more than one librarian to be online simultaneously. Virtual services studied in this research were staffed by only one librarian at a time; therefore there were no instances of consultation. In contrast, study 3 recorded 29 instances of librarians conferring during face-to-face reference. In another 33 cases, patrons were referred to a different librarian. The ability to confer is clearly a benefit of face-to-face reference.

Much of the literature on virtual reference speaks of the lack of nonverbal cues in the online environment. To see if non-verbal cues were affecting the likelihood of instruction, a section was added to the observation matrix in study 3. Observers recorded the physical behaviors and facial expressions of the patron. After recording behaviors, the observers answered "yes" or "no" to the statement, "The patron was interested in learning." Behaviors indicating interest included leaning in toward the librarian, watching the computer screen, taking notes, and engaging in active dialogue with the librarian. Behaviors indicating lack of interest included looking away during the reference transaction, talking on a cell phone, talking with other patrons, and crossing their arms. While these nonverbal behaviors were not necessarily steadfast indicators, librarians could make assumptions about a patron's willingness to accept instruction based on these non-verbal cues.

There were 259 observations in which non-verbal behaviors were recorded. Only 24 percent indicated lack of interest. Surprisingly, five of these patrons actually phrased their initial query in such a way that it was coded as $\mathrm{Cl}$ or $\mathrm{C} 2$ (patron asked for instruction), but their body language told a different story. The majority of the remaining 76 percent indicated interest in learning by non-verbal cues; 66 percent of them also phrased their query as a request for instruction. Did non-verbal cues affect the likelihood of instruction? If a patron appeared uninterested in learning, did the librarian still practice instruction? $\mathrm{Cl}$ divided by the sum of $\mathrm{Cl}$ and $\mathrm{C} 2$ represents the overall rate of instruction when it is asked for: 90 percent $(n=136)$. But, of that group, those who appeared interested in learning received instruction at a slightly higher rate: 92 percent $(n=131)$. For those who appeared uninterested in learning but asked for instruction $(n=5)$, only 40 percent received instruction. C3 divided by the sum of $\mathrm{C} 3$ and $\mathrm{C} 4$ represents the overall rate of instruction when it is not requested: 87 percent $(n=123)$. Yet those who appeared interested in instruction despite not asking for it $(\mathrm{n}=66)$ received instruction at a rate of 97 percent. For those who did not ask for instruction and did not appear interested in it $(\mathrm{n}=57)$, only 75 percent received instruction.

C1 plus C3 divided by the total number of transactions represents the rate of instruction. Analyzed without regard to question format, there was a 94 percent rate of instruction for the 197 patrons who exhibited non-verbal behaviors indicating interest in learning. Similarly, for the 62 patrons who exhibited lack of interest via non-verbal clues, there was a 73 percent rate of instruction. Non-verbal clues did seem to have an impact. In summary, it seems that librarians were influenced by their perceptions of patrons' interest in learn- ing. They are alerted to the teachable moment by both initial query and by body language.

All three studies showed that librarians were providing instruction via the reference transaction. What kinds of instruction were they practicing? Each interaction in all three studies was coded for the following instructional practices:

A. Modeling: Librarian finds and gives the needed information, then outlines the steps to locate it but does not make sure the patron is following along.

B. Resource Suggestion: Librarian suggests print or electronic resources such as the library catalog, a database, or URL.

C. Terms Suggestion: Librarian suggests appropriate keywords, subject headings, Boolean operators, or limits.

D. Leading: Librarian leads the patron step-by-step to the needed information.

E. Lessons: Librarian explains library or research terminology such as the peer-review process.

Multiple codes could be assigned for each transaction because many librarians used multiple instructional techniques in any given transaction. But each code was used only once, despite the number of times it may have occurred during the transaction. Totals for each code were then divided by the total number of transactions to show which were being used most often. Figure 3 shows the results for study 3. Percentages do not equal 100 percent since multiple codes could be used in each transaction.

Librarians practicing face-to-face reference favored leading as an instructional technique. This technique, walking the patron through a process in small sequential steps, occurred in 63 percent of the transactions. Resource suggestion followed with 52 percent. The third most common instructional practice was modeling, with a 47 percent rate. Terms suggestion ranked fourth at 22 percent, and lessons came 


\section{FEATURE}

in last at 17 percent.

Analysis of instructional techniques also was applied to studies 1 and 2 to measure the rate of each technique in the different reference mediums. Did librarians practice different instructional techniques in virtual as opposed to face-to-face reference? Results showed that this was indeed the case. Figure 4 compares the five instructional techniques across all three studies: IM, chat, and face-to-face reference. A chi-square analysis indicates areas of statistical significance.

Figure 4 shows that there were statistically significant differences among the three studies for all instructional techniques except terms suggestion. Modeling occurred much more often in face-to-face interactions, 47 percent of the time, as opposed to 23 percent in both IM and chat, $X^{2}(2, N=537)=$ $34.43, p<.001$. In resource suggestion, face-to-face reference ranked lowest at 52 percent. Librarians in IM were more likely to practice resource suggestion at 60 percent, and chat librarians even more so at 77 percent, $X^{2}(2, N=537)$ $=21.01, p<.001$. Terms suggestion remained comparable across all three mediums at 29 percent, 20 percent, and 22 percent respectively, $X^{2}(2, N=537)$ $=3.46, p=.177$. But study 3 showed another large difference in leading at 63 percent, compared to 42 percent in study 1 and even fewer, 25 percent, in study $2, X^{2}(2, N=537)=49.06, p<.001$. Lessons were the least used instructional practice in all three studies. It ranked highest in face-to-face reference at 17

Figure 3. Study 3

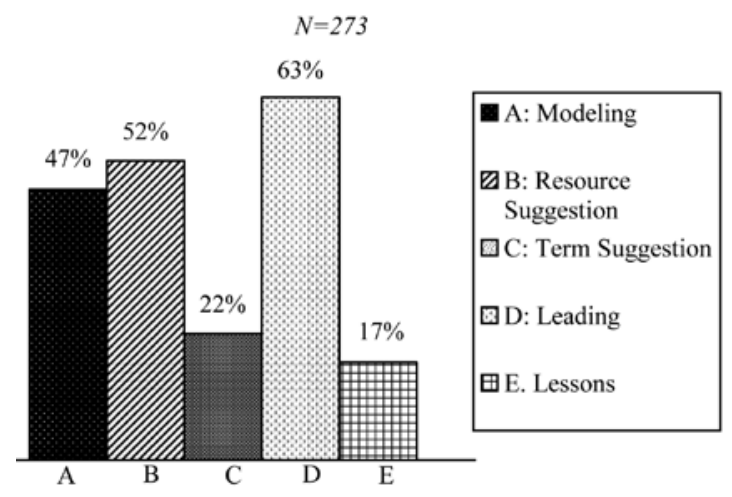

Figure 4. Comparative Analysis of Instructional Methods

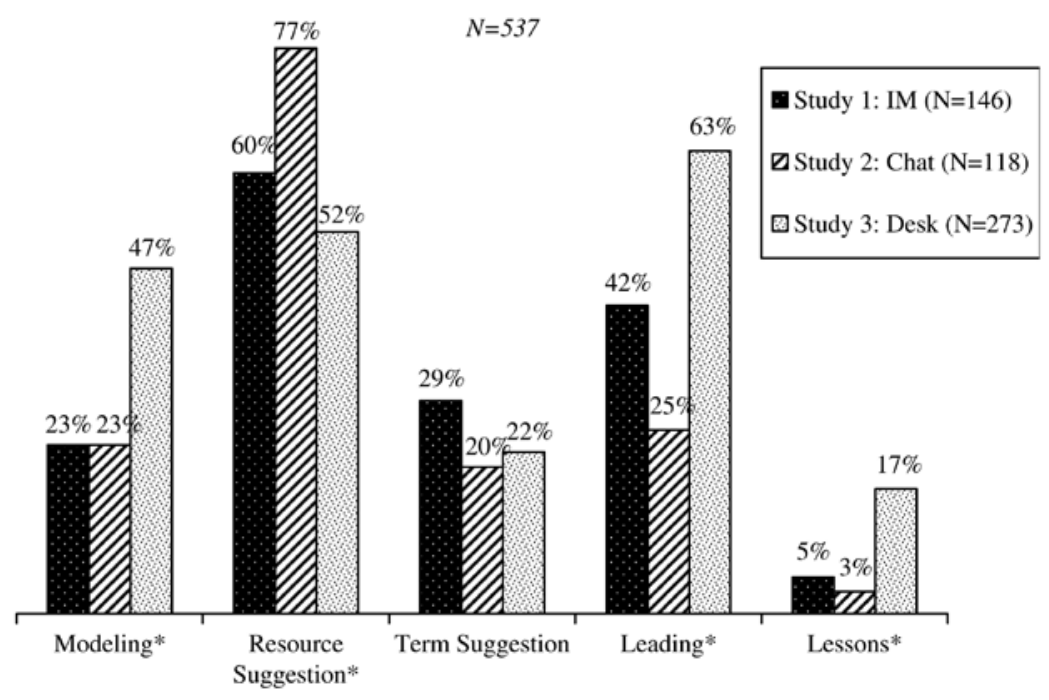

percent, and 5 percent, and 3 percent respectively in studies 1 and $2, X^{2}(2$, $N=537)=23.35, p<.001$.

Clearly, librarians practiced different instructional techniques in different reference mediums. Why? Perhaps some instructional techniques are more suited to in-person reference rather than the online environment. For instance, the explanation for the dramatic increase in lessons (on library terminology or theories and complex processes) during study 3 seems clear. Complex ideas can be more easily conveyed in fluid conversation with a patron whereas the staccato nature of chat makes it impractical to type long paragraphs. Likewise, the rise in modeling and leading could be explained by librarians' comfort with the reference medium, lack of technical difficulties, and the personal nature of face-to-face reference. But more study would be needed for a definitive answer.

Questionable reference practices were also recorded in all three studies. Two specific questionable practices were identified-page pushing and citation pushing. Page pushing was defined as directing a patron to a Web page without explaining how to get there or how the librarian knew to go there. In the virtual environment, librarians can choose to page push by manipulating the patrons' Web browsers. In face-to-face reference, the librarian can click on or go to Web sites without showing or explaining the process to the patron. Citation pushing is similar because librarians give a citation or call number without explaining how they located that source. Both are questionable practices because they preclude instruction. Page pushing occurred in 63 instances in study 1, 0 in study 2 , and 33 in study 3 . In previous analysis, the authors speculated that because of insufficient training, staff may have been unaware of how to push pages in the new chat software used in study 2 . The majority of page pushes in study 3 were instances in which the librarian went directly to the online catalog without explaining what it was or how to gain access to the 
resource. For the novice patron, this is an important first step that should not be ignored. Frequency of citation pushes saw a marked difference in each medium. Study 1 showed 56 counts of citation pushing, study 2 had only 22, and study 3 had fewer still-only 19 . This may be because visual demonstration of citation retrieval is not possible in IM reference, whereas it is feasible in chat with co-browse, and easy in faceto-face reference. Both page pushing and citation pushing showed statistically significant differences across mediums with a $p$ value of $<.001$.

\section{Survey Analysis}

Similar patron surveys were administered in all three studies. The surveys administered in studies 1 and 2 were Web-based; surveys in study 3 were paper-based. Questions relative to cobrowsing capability were added to survey 2 . Likewise, questions relative to the information desk were added to survey 3. Response rates were more generous in the online surveys. Survey 1 had 50 respondents, a 30 percent response rate. Survey 2 had the highest response rate at 62 respondents, or 46 percent. Survey 3 , the paper survey, had 88 , a 16 percent response rate. Survey responses are summarized in table 1 . Morris Messenger refers to the IM and chat services.

Responses from IM and chat users were fairly consistent, but there were notable differences between virtual and physical mediums. First time respondents accounted for over 70 percent of online reference patrons. Survey results showed the opposite was true of physical reference, with 86 percent having used the information desk before. Patrons in all three studies indicated

Table 1. Survey Responses

\section{Survey Responses}

1: IM

$(N=50)$

2: Chat

$(N=62)$

$30 \%$

$70 \%$

$98 \%$

$2 \%$

No

I wanted the librarian to teach me how to find the information myself.

Definitely

Would be nice

Didn't care

No way, find it for me

The librarian showed me how to find the information for myself.

Yes

Sort of

Not at all

I learned something about how to find what I was looking for.

Yes

Sort of

Not at all

Do you think chat/information desk is a good way to learn how to find information?

Yes

No
$46 \%$

$16 \%$

$30 \%$

$8 \%$

$80 \%$

$16 \%$

$92 \%$

$4 \%$

$4 \%$

98\%

$2 \%$
$27 \%$

$73 \%$

$86 \%$

$14 \%$

$99 \%$

$1 \%$

$7 \%$

$55 \%$

$57 \%$

$27 \%$

$10 \%$

$6 \%$

$3 \%$

$71 \%$

$83 \%$

$15 \%$

$2 \%$

$14 \%$

$77 \%$

$88 \%$

$15 \%$

$10 \%$

$8 \%$

$2 \%$

00\%

$0 \%$ 


\section{FEATURE}

willingness to return, an indicator of patron satisfaction. Face-to-face reference received the highest proportion (99 percent) willing to use the service again. IM followed with 98 percent, and chat with 93 percent willingness to return.

Reference librarians may believe in the teachable moment, but do patrons actually want instruction? All three surveys indicated that they do. While all the survey results were similar, more survey respondents at the physical information desk indicated a desire to learn. Of these, 57 percent "definitely" wanted the librarian to teach them how to find information for themselves. This compared to 55 percent in chat and only 46 percent in IM reference. Respondents who indicated instruction "Would be nice" made up an additional 27 percent in both physical and chat reference and 16 percent in IM reference. Apathetic responses ("didn't care") differed with 30 percent in survey 1,15 percent in survey 2 , and only 10 percent in survey 3 . Finally, respondents could answer that they were not interested in instruction and they wished the librarian would "Just find it for me." A small minority preferred this, with 8 percent in IM, 3 percent in chat, and 6 percent at the information desk. Adding "definitely," "would be nice," and "didn't care" responses gave the total number of patrons open to instruction. In all three surveys, over 90 percent of patrons were open to instruction from the librarian.

Survey results also showed that librarians are actively teaching in all three mediums. But more respondents felt they had received instruction at the physical information desk than in the online mediums. When asked if the librarian "showed them how to find the information themselves," 98 percent at the information desk responded positively (combination of "yes" and "sort of" responses). Only 96 percent responded that the librarian provided instruction in the IM survey and only 86 percent in the corresponding chat survey. The difference in the surveys substantiates transcript analysis, which showed that librarians provided more instruction in face-to-face reference than in either chat or IM reference.

Librarians' efforts to teach are not going unnoticed. An overwhelming majority of patrons indicated that they learned from their reference experience in all three mediums. But comparison showed that IM patrons responded most positively that they had learned (92 percent "yes"). Study 2 dipped to 77 percent, and study 3 showed an 88 percent perception of learning. Those who marked the intermediate "sort of" response made up 4 percent, 15 percent, and 10 percent respectively. Combining the two responses shows that over 96 percent perceived they had learned in IM, 92 percent in chat, and 98 percent in face-to-face reference. Clearly, patrons perceived that they were learning from the reference transaction. Collectively, these responses support the authors' belief that instruction can and should be practiced from the reference desk, be it physical or virtual, and that reference instruction can be effective in both.

Finally, respondents were asked if they thought IM, chat, or the information desk was a good way to learn how to find information. Respondents answering "yes" accounted for 98 percent, 92 percent, and 100 percent respectively. Respondents were overwhelmingly positive about the service they received in each medium, and, more importantly, about that service's ability to provide a learning experience. Here again, face-to-face interaction seems to offer a slight edge over virtual mediums.

Survey 2 included questions about patrons' experience with co-browsing technology. Over 90 percent of patrons who reported using co-browsing thought it was a good way to learn. The other 10 percent thought that cobrowsing was "too confusing." Surprisingly, respondents seemed enthusiastic about co-browsing even though transcript analysis showed a large number of technical difficulties. Perhaps the high rate of satisfaction with co-browsing is attributable to its visual nature. If patrons can see what the librarian is doing and can participate via a shared browser, they may feel they can later repeat the process. Co-browsing allows for textual explanation via the chat window and visual cues in the shared browser window. Certainly its ability to provide for multiple learning styles is an asset.

The authors were curious how the act of co-browsing might mimic behaviors commonly practiced in face-toface reference. In addition to questions found in all three surveys, survey 3 also contained a question asking patrons if the librarian involved them in the search process. Of the eighty-eight responses, only one indicated that the librarian did not involve him or her in the search process. Another two did not answer the question. This left eightyfive (97 percent) who marked "Yes, the librarian involved me in the search process." These respondents were asked to indicate how the librarian involved them by selecting from a series of behaviors such as pointing to an area on the computer screen or turning the monitor so that the patron could see. Respondents could choose as many as applied to their reference experience. Fourteen respondents did not select any of the behaviors from the list, despite marking "yes" to the previous question. Therefore totals are based on the remaining 71 respondents.

All 71 respondents (100 percent) indicated that the librarian turned the computer monitor towards them so that they could follow the search. Another 57 (80 percent) noted the librarian pointed to an area on the monitor. The next-highest ranked behavior was pointing to an area in the library, with 39 patrons (55 percent) reporting that the librarian used this technique. Only 23 patrons (32 percent) reported that the librarian encouraged them to type on the keyboard or use the mouse. Finally, one respondent selected the "Other" category for a write-in comment, stating that the librarian demonstrated how to renew books. Most respondents indicated that the librarian practiced two or more of the above behaviors.

These behaviors at the information desk are comparable to a co-browsing session because the patron can be involved on multiple levels. Like 
co-browsing, involvement at the information desk begins by viewing the computer screen together. But transcript analysis does not allow us to see each and every keystroke in the co-browse session, so the level of involvement is not as easily measured. Co-browsing attempts to mimic common behaviors at the desk but cannot duplicate simple physical actions such as pointing to an area in the library. Features in co-browsing, such as the ability to point to areas of the screen with an arrow, are complicated by technology. Librarians and patrons alike must learn to use the technology while still trying to teach and learn. The simplicity of the information desk makes these actions far easier and thus more likely to occur.

\section{CONCLUSION}

Since the advent of complex end-user databases, the once active debate over the instructive role of reference librarians seems passé. These three studies indicate that patrons wanted to be taught regardless of medium, and that librarians responded by providing instruction in all mediums. These patrons' consistently high desire for instruction reinforces the notion that the ideal teachable moment can be found in reference work. Reference queries are patron initiated and can engage the student in point-of-need active learning.

The question then becomes how should we teach? What techniques are librarians using, what teaching models are they following, and what instructional behaviors are effective in the reference situation? This study attempts to begin this discussion by providing preliminary data on one library's instructional techniques. One difference between virtual and physical reference does stand out. Instructional techniques measured were used in different proportions in each medium. While professional best-practice guidelines such as RUSA's "Guidelines for Behavioral Performance of Reference and Information Service Providers" dictate consistency of service regardless of medium, librarians need to recognize that instructional techniques may not be a one-size-fits-all proposition. Different reference mediums may call for different teaching techniques to maximize effective learning.

The findings above draw attention to differences in instructional practices, mediums, and behaviors. Yet the most striking feature of the data is the similarity in the findings. In all mediums, librarians provided instruction almost all the time, whether the patron seemed to be asking for it or not. The phrasing of the question and the non-verbal behaviors of the patrons did have some effect on the likelihood of instruction, but according to transcript analysis, that effect was small. Librarians in virtual reference were almost as likely to provide instruction as those at the information desk, and paraprofessionals almost as often as degree-holding librarians. Patrons for the most part expressed a desire to learn and felt that reference is an effective tool for learning. They were happy with the reference transaction and ready to return. Patrons who visited the library physically were slightly more satisfied than those who visited virtually. While both numbers were quite high, it is interesting to note that the information desk saw slightly higher rates of instruction and user satisfaction.

Further study is needed to determine how instruction is being practiced through reference work. Librarians perform a disservice to patrons if instruction in reference transactions is only a happy accident, practiced without deliberation, research, or care. Library-school courses in reference typically focus on sources and reference interview techniques, ignoring the instructive aspect of reference. Greater attention to learning theory in library school is a must, not only in courses on instruction but also in reference classes. With the recent explosion in libraries' virtual reference presence, further study also is warranted to measure the effectiveness of various teaching techniques and their relationship to differing reference mediums. As reference mediums evolve, librarians will not only have to learn to recognize the "teachable moment" but also to identify strategies to maximize learning potential in each medium.

\section{References and Notes}

1. Encarta World English Dictionary, North American Edition, http://encarta.msn. com/dictionary_561539567/teachable_ moment.html (accessed May 16, 2007).

2. Reference and User Services Association, "Guidelines for Behavioral Performance of Reference and Information Service Providers," www.ala.org/ala/rusa/rusaprotools/referenceguide/guidelinesbehavioral.htm (accessed May 16, 2007).

3. Christina M. Desai and Stephanie J. Graves, "Instruction via Instant Messaging: What's Happening?" The Electronic Library 24, no. 2 (2006): 174-89.

4. Stephanie J. Graves and Christina M. Desai, "Instruction via Chat: Does Cobrowse Help?" Reference Services Review 34, no. 3 (2006): 340-57.

5. JoAnn Jacoby and Nancy P. O'Brien, "Assessing the Impact of Reference Services Provided to Undergraduate Students," College and Research Libraries 66, no. 4 (July 2005): 331.

6. Anita Rosenbaum Schiller, "Reference Service: Instruction or Information," Library Quarterly 35 (Jan. 1965): 52-60.

7. Bill Katz, "Long Live Old Reference Services and New Technologies," Library Trends 50, no. 2 (Fall 2001): 267.

8. Ibid., 270.

9. Anita R. Schiller, "Reference Service: What's Changed," The Reference Librarian nos. 1/2 (Fall/Winter 1981/1982): 5.

10. Carol Tenopir, "Impacts of Electronic Reference on Instruction and Reference," The Impact of Technology on Library Instruction: Papers and Session Materials Presented at the Twenty-first National LOEX Library Instruction Conference held in Racine, Wisconsin, 14 to 15 May 1993, ed. Linda Shirato (Ann Arbor, Mich.: Pierian Press, 1995), 5-6.

11. For examples, see Keith Ewing and Robert Hauptman, "Is Traditional Reference Service Obsolete?" The Journal of Academic Librarianship 21 (Jan. 1995): 3-6; and David W. Lewis, "Traditional Reference is Dead, Now Let's Move on to Important Questions," The Journal of Academic Librarianship 21 (Jan. 1995): $10-12$.

12. Charity B. Hope, Sandra Kajiwara, and Mengxiong Liu, "The Impact of the Internet: Increasing the Reference Librarian's Role as Teacher," The Reference Librarian no. 74 (2001): 13-36.

13. David Tyckoson, "What We Do: Reaffirming the Founding Principles of Reference Services," The Reference Librarian no. 59 (1997): 10. 


\section{FEATURE}

14. Alex Lankester, "What We Know about ScienceDirect User Behavior," Library Connect 4 (Jan. 2006): 10-11.

15. Melissa Gross, "The Impact of Low-level Skills on Information-seeking Behavior," Reference \& User Services Quarterly 45, no. 2 (Winter 2005): 155-62.

16. Virginia Massey-Burzio, "From the Other Side of the Reference Desk: A Focus Group Study," The Journal of Academic Librarianship 24, no. 3 (May 1998): 212.

17. E. Stewart Saunders, "The Effect of Bibliographic Instruction on the Demand for Reference Services," portal: Libraries and the Academy 3, no. 1 (Jan. 2003): 38.

18. Camille McCutcheon and Nancy M. Lambert, "Tales Untold: The Connection between Instruction and Reference Services," Research Strategies 18, no. 3 (2001): 203-14.

19. James K. Elmborg, "Teaching at the Desk: Toward a Reference Pedagogy," portal: Libraries and the Academy 2, no. 3 (2002): 455.

20. Ibid., 459.

21. Reference and User Services Association, "Guidelines for Behavioral Performance of Reference and Information Service Providers," www.ala.org/ala/rusa/rusaprotools/referenceguide/guidelinesbehavioral.cfm (accessed May 16, 2007).

22. Shannon L. Roper and Jeannette Kindred, "IM here' Reflections on Virtual Office Hours," First Monday 10, no. 11 (2005), www.firstmonday.org/issues/issue10_11/ roper (accessed July 24, 2006); Ladonna Guillot and Beth Stahr, "One Step Further: Virtual Instruction Strategies, Connection," Louisiana Libraries 67, no. 4 (Spring 2005): 8-11.

23. Desai and Graves, "Instruction via Instant Messaging"; Graves and Desai, "Instruction via Chat."; Susan E. Beck and Nancy B. Turner, "On the Fly BI: Reaching and Teaching from the Reference Desk," The Reference Librarian no. 72 (2001): 83-89; Denise D. Green and Janis K. Peach, "Assessment of Reference Instruction as a Teaching and Learning Activity," College and Research Libraries News 64, no.
4 (April 2003): 256-58; Lisa A. Ellis, "Approaches to Teaching Through Digital Reference," Reference Services Review 32, no. 2 (2004): 103-19; David Ward, "Why Users Choose Chat: A Survey of Behavior and Motivations," Internet Reference Services Quarterly 10, no. 1 (2005): 29-46; Beth S. Woodard, "One-on-one Instruction: From the Reference Desk to Online Chat," Reference \& User Services Quarterly 44 , no. 3 (Spring 2005): 203-9.

24. Jody Condit Fagan and Christina M. Desai, "Communication Strategies for Instant Messaging and Chat Reference Services," The Reference Librarian nos. 79/80 (2002/2003): 121-55.

25. David S. Carter, "Hurry Up and Wait: Observations and Tips about the Practice of Chat Reference," The Reference Librarian nos. 79/80 (2002/2003): 119.

26. Kelly M. Broughton, "Usage and User Analysis of a Real-time Digital Reference Service," The Reference Librarian nos. 79/80 (2002-2003): 183-99.

27. Jane Ronan, Patrick Reakes, and Gary Cornwell, "Evaluating Online Real-time Reference in an Academic Library: Obstacles and Recommendations," The Reference Librarian nos. 79/80 (2002/2003): 225-40.

28. Fu Zhuo, Mark Love, Scott Norwood, and Karla Massia, "Applying RUSA Guidelines in the Analysis of Chat Reference Transcripts," College and Undergraduate Libraries 13, no. 1 (2006): 75-88.

29. Amy Paster, Kathy Fescemyer, Nancy Henry, Janet Hughes, and Helen Smith, "Assessing Reference: Using the Wisconsin-Ohio Reference Evaluation Program in an Academic Science Library," Issues in Science and Technology Librarianship 46 (Spring 2006), www.istl.org (accessed May 16, 2007).

30. Eric Novotny, "Evaluating Electronic Reference Services: Issues, Approaches and Criteria," The Reference Librarian no. 74 (2001): 103-20.

31. Peter R. Hernon and Charles R. McClure, "Unobtrusive Reference Testing: The 55 percent Rule," Library Journal 111 (Apr. 15, 1985): 37-41.

32. Joan C. Durrance, "Factors That Influence Reference Success: What Makes Questioners Willing to Return?" The Reference Librarian nos. 49/50 (1995): 243-65.

33. F. J. Roethlisberger and William J. Dickson, Management and the Worker (Cambridge, Mass.: Harvard Univ. Pr., 1939).

34. H. M. Parsons, "What Happened at Hawthorne?" Science 183 (Mar. 8 1974): 922-32.

35. Ibid., 927

36. For examples, see John G. Adair, "The Hawthorne Effect: A Reconsideration of the Methodological Artifact," Journal of Applied Psychology 69, no. 2 (May 1984): 334-45; Gordon Diaper, "The Hawthorne Effect: A Fresh Examination," Educational Studies 16, no. 3 (1990): 261-67; and Stephen R. G. Jones, "Was There a Hawthorne Effect?" The American Journal of Sociology 98, no. 3 (Nov. 1992): 451-68.

37. Adair, "The Hawthorne Effect: A Reconsideration," 342-43.

38. Jo Bell Whitlatch, "Unobtrusive Studies and the Quality of Academic Library Reference Services," College and Research Libraries 50 (Mar. 1989): 183-84.

39. Bruce Jensen, "The Case for Non-Intrusive Research: A Virtual Reference Librarian's Perspective," The Reference Librarian no. 85 (2004): 142.

40. Jo Bell Whitlatch, "Evaluating Reference Services in the Electronic Age," Library Trends 50, no. 2 (Fall 2001): 212.

41. Ibid., 208.

42. Desai and Graves, "Instruction via Instant Messaging."

43. Ibid.; Graves and Desai, "Instruction via Chat."

44. Graves and Desai, "Instruction via Chat," 349. Note: Rates of instruction when instruction was not requested were incorrectly reported as 77 percent and 68 percent in this article. The error has been corrected in the present article.

45. Ibid., 351 . 